\title{
Oxygen Consumption during Different Exercise Protocols in the Aged
}

Mark R McKean*, Timothy B Stockwell and Brendan J Burkett

Faculty of Science, Health, Education and Engineering, University of Sunshine Coast, Queensland, Australia

\begin{abstract}
Objectives: The objective of this study was to compare response; specifically oxygen consumption; of a single bout of exercise using two different (constant and interval) intensity protocols in an aged population.

Design: Ten males $(68.8 \pm 3.7$ years $)$ and six females $(66.2 \pm 3.5$ years $)$ were recruited for this study. All participants were actively involved in three hours of physical activity per week and were able to use a cycle ergometer unaided.

Methods: Participants completed two randomised $20 \mathrm{~min}$ exercise protocols on a cycle ergometer, each with equal work output. The constant intensity session was at $50 \%$ of $V_{0}$, and the 1 min interval session varied from $70 \%$ to $30 \%$ Vo . Oxygen consumption was measured during the following phases; resting, warm-up, exercise, cooldown and 20 mins post-exercise.
\end{abstract}

Results: Similar values were found when comparing the overall oxygen consumption for the constant and interval protocols respectively. However, significant differences $(p<0.05)$ were found between the two different intensities during the exercise phase.

Conclusions: The interval training protocol consumed higher levels of oxygen during the exercise phase when compared to the constant intensity protocol, despite the participants reporting similar RPE. These age-specific differences should be considered for future exercise prescription for this at-risk population.

Keywords: Aged; Exercise test; Energy expenditure; EPOC

\section{Introduction}

Regular physical activity has been linked to reductions in the risk factors for chronic disease and disability [1]. The aging process, however, tends to decrease the intensity and duration of spontaneous physical activity [2] and also the decline in functional capacity [3]. These factors have been linked to the reduction in the quality of life from the second to the seventh decade of life [4] as well as a decrease in muscle mass every year from the fourth decade of life [5].

Traditionally, exercise protocols of intensity and duration have been determined for a broad and general population, and from this information the protocols are extrapolated and assumed to be suitable for other populations, such as the at-risk aged population. Health practitioners have previously avoided using interval training in the past due to concerns over increased heart rates and stress which are held at an even level during constant cardiovascular training sessions in comparison. With recent research supporting the use of interval training for increased cardiovascular effect $[6,7]$, patients with COPD [8,9], and fat oxidation [10] health practitioners may need to reconsider the use of interval training methods in other low risk populations. The aging population is one such group of people who are looking for ways to maintain good health and participate in a range of fitness activities and evidence suggests these leisure-time activities are an important promoter of health [11]. The mode of exercise can influence oxygen consumption, with differences in the physiological responses found between a single continuous exercise protocol and three different intermittent exercise protocols [12]. The three intermittent training protocols, at both $50 \%$ and at $70 \% \mathrm{Vo}_{2 \text { Peak }}$, showed significantly lower heart rate, minute ventilation and $\mathrm{Vo}_{2}$ when compared to a similar amount of work done within the constant load protocols. This finding suggests that intermittent training is more efficient than constant load training. However, there were no significant differences found between the 15, 30 , and 60 second intermittent protocols, when compared to each other. Furthermore, heart rate, minute ventilation and $\mathrm{Vo}_{2}$ were only taken at the mid-point of each stage of exercise, which meant that the total expired gas and energy expenditure for the entire duration of exercise were not examined. A similar finding was made when comparing constant walking or high-intensity interval walking, with highintensity interval walking resulting in greater increases in $\mathrm{Vo}_{2 \text { Peak }}[13]$. If high-intensity interval walking helps to protect older persons against some of the age-related reductions in muscle strength and $V_{\mathrm{o}_{2 \text { Peak }}}$, exercise prescription should encourage a high-intensity component during walking. For the sedentary aged population the problems of joint degeneration and the associated high ground force impact from walking may inhibit this mode of physical activity. Consequently the low impact and simple nature of cycle ergometers are often preferred by people with orthopaedic disabilities of the lower extremities, which are more prevalent in elderly people than younger populations. To date, there is little literature which specifically examines the differences in total oxygen consumption during exercise between constant load and interval training in the elderly (65 years and older). This lack of knowledge for what is an important aspect of exercise, particularly in such a crucial population as the elderly, has left many questions unanswered, especially in regards to exercise efficiency and the short-term physiological responses of exercise[14]. This knowledge will facilitate the global aging process [15] and will help to maintain improved health and wellbeing. Reductions in $\mathrm{Vo}_{\mathrm{m}_{\max }}$ in nonendurance-trained individuals are thought to be justified by the loss of muscle mass, which is observed with advancing age [16]. Regular activity is known to reduce the risk factors of chronic disease and disability, and the aging process is known to correlate with a reduction in physical activity, further reinforcing the need for exercise protocols for the elderly that are not only efficient but also beneficial.

*Corresponding author: Mark McKean, Faculty of Science, Health, Education and Engineering, University of Sunshine Coast, Queensland, Australia, Tel: +61 7 54565528; Fax: +61 54564600; E-mail: mmckean@usc.edu.au

Received June 25, 2018; Accepted August 09, 2012; Published August 13, 2012

Citation: McKean MR, Stockwell TB, Burkett BJ (2012) Oxygen Consumption during Different Exercise Protocols in the Aged. J Sports Med Doping Stud 2:114 doi:10.4172/2161-0673.1000114

Copyright: (c) 2012 McKean MR, et al. This is an open-access article distributed under the terms of the Creative Commons Attribution License, which permits unrestricted use, distribution, and reproduction in any medium, provided the original author and source are credited. 
Therefore, the objectives of this study were to directly examine the differences in oxygen consumption, perceived effort and efficiency in the elderly using cycle ergometers across two different protocols, constant and interval. The authors hypothesized there will be little or no difference for oxygen consumption and perceived effort for the interval protocol compared with the constant protocol.

\section{Materials and Methods}

Ten males (aged $68.8 \pm 3.7 \mathrm{y}$, height $173.7 \pm 7.5 \mathrm{~cm}$, weight $85.2 \pm$ $17.6 \mathrm{~kg}$ and predicted $\left.V_{\mathrm{o}_{2 \max }} 36.4 \pm 5.2 \mathrm{ml} . \mathrm{kg}-1 . \mathrm{min}-1\right)$ and six females (aged $66.2 \pm 3.5 \mathrm{y}$, height $163.4 \pm 6.9 \mathrm{~cm}$,weight $69.3 \pm 8.6 \mathrm{~kg}$ and predicted $V \mathrm{o}_{2 \max } 32.8 \pm 5.5 \mathrm{ml} . \mathrm{kg}$-1.min-1) were recruited to participate in this study. Participants were informed of the research risks and 11 signed University ethics committee approved consent forms before data were collected.

All participants were active, currently participating in a minimum of three hours of physical activity per week, and able to use a cycle ergometer unaided. Additionally, participants were not on any medication that would inhibit any physical activity, and were classified in the 'moderate' category through the risk stratification process [17].

Participants were tested on three separate mornings, having fasted overnight. Participants were also requested to refrain from strenuous exercise and activity on the preceding day to testing. The first session involved a pre-exercise screening questionnaire [17], a 20 min supine resting 12-lead echocardiogram (ECG) and a sub-maximal fitness assessment. All participants were classified as 'moderate risk' due to their age; however they did not require medical clearance due to the relative sub-maximal nature of the exercise being performed. The 12lead ECG placement was as per standard protocol [18]. Participants were required to rest in a supine position for $20 \mathrm{~min}$, after which time a sample heart trace was taken and assessed for any abnormalities.

Participants then undertook a sub-maximal $\mathrm{Vo}_{2}$ test to predict their $V_{\mathrm{O}_{2 \max }}$. The test was performed on a cycle ergometer (Jaeger ER800, Bitz, Germany). The test commenced with participants cycling at 60 revolutions per minute (rpm) for 3 mins at $20 \mathrm{~W}$. The resistance was then increased to $50 \mathrm{~W}$ for 2 mins, and then a further $25 \mathrm{~W}$ every subsequent 2 mins until participant's heart rate reached $75 \%$ of their age-predicted maximal heart rate, using the formula; $208-[0.7 \times$ age $]$ [19], or until they were unable to continue to pedal at $60 \mathrm{rpm} . V_{\mathrm{o}_{2 \max }}$ was calculated by extrapolation using the Multi-stage Model [20]. These values were used to base the percent effort protocol of the two 'exercise' sessions. Heart rate was measured and rating of perceived exertion (RPE) was taken during the last $5 \mathrm{~s}$ of each stage for safety and comfort reasons. The second and third morning exercise sessions consisted of either the constant or interval exercise protocol, which was randomised to eliminate any bias from protocol order. Subsequent to each of the two 'exercise' sessions, participants completed another resting 12-lead ECG to ensure consistency and accuracy of initial readings.

Expired gas samples were collected in $15 \mathrm{~s}$ averages through a one-way non re-breather mask (Hans-Rudolph 7930 breathing valve, Kansas City, MO, USA) and analysed using a calibrated TrueMax 2400 metabolic measurement system (Parvo Medics, Sandy, UT, USA) as per existing protocol. The gas collection in each session was broken up into five different phases; (i) resting baseline, (ii) warm-up, (iii) exercise, (iv) cool-down, and (v) post-exercise resting. Baseline values were collected with participants seated on the cycle ergometer at rest. This was followed by the warm-up, which consisted of 2 mins of $60 \mathrm{rpm}$ pedalling at $20 \mathrm{~W}$. The exercise phase involved 20 mins of pedalling at $50 \%$ of extrapolated $V_{\mathrm{o}_{2 \max }}$ for the constant session, or 20 mins alternating $70 \% \mathrm{Vo}_{2 \max }$ for 1 min followed by $1 \mathrm{~min}$ of $30 \% \mathrm{Vo}_{2 \max }$ in the interval session. Participants were asked to indicate their (RPE) using the 6-20 Borg [21] scale after each minute of exercise in the exercise phase. The cool-down involved 2 mins at $20 \mathrm{~W}$, and the post-exercise collection phase was 20 mins of supine resting. All protocols for the two exercise sessions, pre and post-exercise, were identical with the exception of the 'exercise' phase of the session. Data was analysed using two-way analysis of variations (ANOVA) and is reported as means with $95 \%$ confidence intervals, upper and lower bounds where applicable. Changes in effect statistics are presented in raw and percentage changes.

\section{Results}

Total oxygen consumption and heart rate, broken up into the five phases, for both protocols are shown in table 1. Mean values for oxygen consumption were found to be similar between the two protocols for all subjects. Table 2 presents the effect changes expressed as raw and percentage differences between oxygen consumption and heart rate across the two protocols. Whilst there were no significant differences here, it was shown that the EPOC phase of gas analysis was $11.8 \%$ greater in the interval session when compared to the constant session. Figure 1 illustrates the total oxygen consumption comparisons between the two protocols. The means of the two oxygen consumptions for the entire sessions did not show any significant differences $(\mathrm{p}=0.627)$ However, when the $15 \mathrm{~s}$ averages were compared between the two sessions, significant differences $(\mathrm{p}<0.001)$ were seen relating to constant $(28.3 \mathrm{~L})$ and interval $(30.0 \mathrm{~L})$ data. Males and females showed similar values across most of the other data, except for heart rates during the exercise $(\mathrm{p}=0.029)$ and cool-down $(\mathrm{p}=0.021)$ phases in the constant

\begin{tabular}{|c|c|c|c|c|c|c|c|c|}
\hline \multirow{3}{*}{$\begin{array}{c}\text { Period } \\
\text { Pre (0-2 min) }\end{array}$} & \multicolumn{4}{|c|}{$\mathrm{O}_{2}$ Consumption (Litres) } & \multicolumn{4}{|c|}{ Heart Rate (bpm) } \\
\hline & \multicolumn{2}{|c|}{ Constant $(50 \%)$} & \multicolumn{2}{|c|}{ Interval (70\%:30\%) } & \multicolumn{2}{|c|}{ Constant (50\%) } & \multicolumn{2}{|c|}{ Interval (70\%:30\%) } \\
\hline & 0.31 & $(0.24-0.38)$ & 0.30 & $(0.22-0.38)$ & 63.61 & $(58.17-69.05)$ & 66.29 & $(60.81-71.77)$ \\
\hline Warm Up (2-4 min) & 0.81 & $(0.68-0.95)$ & 0.84 & $(0.68-0.99)$ & 73.19 & $(68.69-77.68)$ & 74.97 & $(70.26-79.69)$ \\
\hline Exercise (4-24 min) & 21.46 & $(17.26-25.65)$ & 22.67 & $(18.93-26.42)$ & 104.65 & $(100.25-109.05)$ & 105.56 & $(100.89-110.23)$ \\
\hline Cool Down (24-26 min) & 1.60 & $(1.30-1.89)$ & 1.52 & $(1.20-1.76)$ & 98.78 & $(94.16-103.40)$ & 96.97 & $(91.04-102.91)$ \\
\hline Post (26-46 min) & 4.15 & $(3.26-5.04)$ & 4.64 & $(3.62-5.66)$ & 73.75 & $(68.47-79.03)$ & 74.21 & $(69.11-79.31)$ \\
\hline
\end{tabular}

Table 1: Oxygen consumption and heart rate during the five phases of gas collection for constant and interval protocols presented as means (95\% $\mathrm{Cl})$.

\begin{tabular}{|c|c|c|c|c|c|c|c|c|}
\hline \multirow[b]{2}{*}{ Pre (0-2 min) } & \multicolumn{2}{|c|}{ Difference (Litres) } & \multicolumn{2}{|c|}{$\%$ Difference } & \multicolumn{2}{|c|}{ Difference (bpm) } & \multicolumn{2}{|c|}{$\%$ Difference } \\
\hline & -0.01 & $(-0.07-0.04)$ & $-3.2 \%$ & $(-37.1-18.6)$ & 2.68 & $(0.45-4.90)$ & $4.2 \%$ & $(0.5-8.2)$ \\
\hline Warm Up (2-4 min) & 0.03 & $(-0.11-0.16)$ & $3.7 \%$ & $(-15.0-30.0)$ & 1.78 & $(0.17-3.40)$ & $2.4 \%$ & $(0.1-4.7)$ \\
\hline Exercise (4-24 min) & 1.22 & $(-0.63-3.06)$ & $5.7 \%$ & $(-12.5-54.9)$ & 0.91 & $(-1.18-2.99)$ & $0.9 \%$ & $(-1.1-2.8)$ \\
\hline Cool Down (24-26 min) & -0.08 & $(-0.26-0.10)$ & $-5.0 \%$ & $(-24.6-50.9)$ & -1.81 & $(-4.75-1.13)$ & $-1.8 \%$ & $(-5.1-1.0)$ \\
\hline Post $(26-46 \mathrm{~min})$ & 0.49 & $(-0.58-1.56)$ & $11.8 \%$ & $(-16.3-47.6)$ & 0.46 & $(-1.51-2.43)$ & $0.6 \%$ & $(-1.9-3.3)$ \\
\hline
\end{tabular}

Table 2: Comparison of interval to constant protocols for oxygen consumption and heart rate presented as absolute and percentage differences (95\% $\mathrm{Cl})$. 


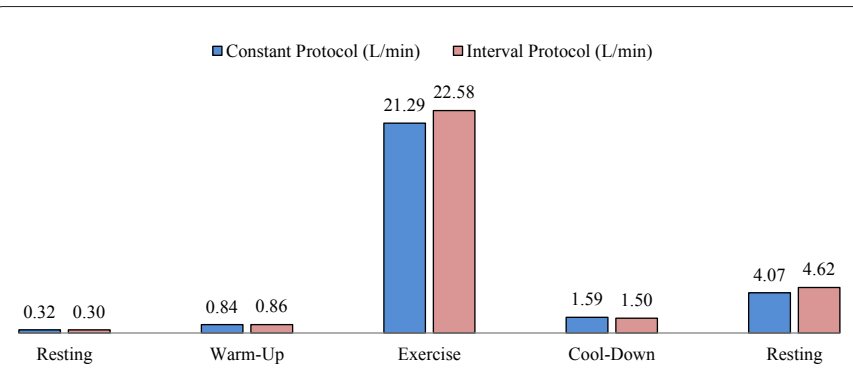

Comparison of Oxygen Consumption per Section

Figure 1: Oxygen consumption (L/min) during the five phases of gas collection for constant and interval protocols presented as means.

protocol, and the warm-up $(\mathrm{p}=0.013)$, exercise $(\mathrm{p}=0.009)$ and cooldown $(\mathrm{p}=0.050)$ phases of the interval protocol.

Most of the participants (10 of the 16 in the constant protocol, and 11 of the 16 in the interval protocol) returned to within 1 standard deviation (SD) of mean pre-exercise oxygen consumption levels within the 20 mins of post-exercise gas collection. Three more returned to within 2 SD in both protocols, with only a small minority $(<18 \%)$ not returning to within either of these ranges of their baseline levels during the $20 \mathrm{~min}$ post-exercise data collection phase.

The mean magnitude of the constant protocol EPOC was found to be $13.6 \%$ of the total oxygen consumption for the session and the exercise component of this same session was found to be $71.1 \%$ of the total oxygen consumption. This resulted in the ratio of EPOC to exercise oxygen consumption for the constant session being 1:5.2 (19.1\%). Similarly, the mean magnitude of the interval protocol EPOC was found to be $15.2 \%$, the exercise component was found to be $75.6 \%$, and the resultant ratio of EPOC to exercise oxygen consumption for the interval session was 1:4.9 (20.5\%).

Average RPE's for both exercise phases of the different protocols were almost identical with the exercise phase of constant session being 11.4, and the interval session being 11.3. This average is consistent with an RPE just above the 'light' level of exertion in both protocols.

\section{Discussion}

The objective of this study was to directly examine the differences in oxygen consumption, perceived effort and efficiency in the elderly using cycle ergometers across two different protocols, constant and interval. The mean oxygen consumption was found to be slightly higher for the interval protocol when compared to the constant intensity of identical work output, with mean consumption readings of 30.0 and $28.3 \mathrm{~L}$ respectively, although these differences were not statistically significant. However, significant differences $(p<0.05)$ were found in the $15 \mathrm{sec}$ oxygen consumption samples between the two different intensities during the exercise phase, with the interval protocol eliciting higher oxygen consumption. No comparable studies were found that assessed elderly male and female participants with a similar mean age of around 67 , however past research conducted on 12 physically active 30 year-old males concluded the interval exercise session generated significantly higher oxygen consumption during exercise [22]. Whilst this other study had protocols that involved slightly higher intensities and longer durations, it does not explain the lack of significant differences in oxygen consumption found in this current study. This leads the authors to believe that age has a potential influence in the differences of oxygen consumption in relation to exercise. The similar values of EPOC across both genders, and both protocols of similar work output found in the current study, highlight the conflict in previous research into this area. These results are supported by earlier studies where similar EPOC values were found [22], but in conflict with another study [23] which found that both duration and magnitude of EPOC are significantly greater for interval exercise when compared to constant protocols. This study indicated that, in a younger male population, interval exercise would be more advantageous in regards to exercise energy expenditure and oxygen consumption. This suggests that the EPOC response may be specific to the participants with respect to age, along with the intensity and duration of exercise.

This current study found similar gender-based values in the analysis performed on oxygen consumption, implying that males and females in an aged population will both use the same amount of oxygen during exercise, and therefore gain similar relative physiological benefits from either constant or interval-based exercise protocols. The effect of gender on oxygen consumption has not yet been fully clarified [24] and the authors were unable to find any other studies that found similar results comparing oxygen consumption in males and females within a similar age group.

The similar values from this current study are contradicted by an earlier study [25] on younger participants (males $21.1 \pm 3.6$ years and females $20.4 \pm 3.1$ years) which showed a significantly higher amount of oxygen consumption in males when compared to the women for $40 \%$ (16.3 to $12.1 \mathrm{~L}), 50 \%$ (22.1 to $21.8 \mathrm{~L}$ ) and $70 \%$ (28.1 to $24.3 \mathrm{~L})$ protocols respectively. In all three protocols, steady-state energy expenditure, and therefore oxygen consumption, was significantly higher in the males than the females. These results imply that a combination of age and gender result in a leveling out, or balancing, effect of oxygen consumption seen with advancing age.

The males and females in this current study had similar ages and also presented similar $V \mathrm{o}_{2 \max }$ scores $(\mathrm{p}=0.11)$, which indicates no difference in physical performance due to gender. The current study exercise phase was $20 \mathrm{~min}$, which would be classified as aerobic or endurance type activity. A similar finding of no difference between genders in an aged population was reported when comparing the endurance swimming performance across genders [25]. Differences however were found in the short sprint swimming events. This indicates that the declines which are associated with age in the physiological influences of sprinting and endurance performance may occur at different rates and at different ages in men and women. A relative rate of the decline in maximal oxygen consumption, which is a key determinant of endurance performance, is similar in both men and women, and therefore further supports the findings of the current study.

This study examined EPOC as a percentage of total oxygen consumption during the two exercise session, with outputs of $14.7 \%$ and $15.5 \%$ during the constant and interval sessions respectively. These values are within previously reported study which found EPOC of nine healthy participants' percentages to be between $7 \%$ and $21 \%$ during cycling [26]. These results support the current studies results in regards to the percentage of EPOC to overall total oxygen consumption.

This current study also examined EPOC as a percentage of exercise phase oxygen consumption, and participants achieved values of $19.3 \%$ during constant exercise and $20.5 \%$ during interval exercise. The previous study found that EPOC in six healthy males was proportional to exercise duration and equalled around $5.1 \%$ after $20 \mathrm{~min}$ of exercise [27]. These results are not similar to the results of the current study and suggest that healthy males either consume a much smaller amount of oxygen during EPOC, or they consume a much higher amount of oxygen during exercise. 


\section{Conclusion}

Increased life expectancy within the global aging process, combined with the degrading and potentially debilitating effects associated with aging make exercise of any description a priority later on in life. Associated with this at-risk population is the need to develop age-specific protocols. Furthermore, to overcome the de-motivation to exercise necessitates the development of efficient protocols with 'high benefit' versus 'low effort' exercise need to be developed. There has been conflicting results from previous research as to which type of exercise, constant or interval shows the greater benefits in regards to either aerobic capacity or immediate physiological effects. Similar mean values were found in this study's oxygen consumption measures, however a significant increase in $15 \mathrm{~s}$ average oxygen consumption was found for the variable intensity exercise protocol. The similar perceived effort for either exercise protocol suggests the aged population will benefit more by engaging in variable intensity exercise. The author's research hypothesis was proven to hold true in that there was little difference between constant and interval protocols for the elderly.

\section{Acknowledgements}

The authors would like to thank Dr. Christopher Askew and Dr. Dale Lovell for their expertise and assistance in this project.

\section{References}

1. Warburton DE, Nicol CW, Bredin SS (2006) Prescribing exercise as preventive therapy. CMAJ 174: 961-974.

2. Prentice AM (1992) Energy expenditure in the elderly. Eur J Clin Nutr 46: S21-28.

3. Chatard J, Denis C (1994) Physical fitness of elderly = Physical fitness of elder people. Ann Phys Rehabil Med 37: 423-429.

4. Vaughan L, Zurlo F, Ravussin E, (1991) Aging and energy expenditure. Am J Clin Nutr 53: 821-825.

5. Seguin R, Nelson ME (2003) The benefits of strength training for older adults. Am J Prev Med 25: 141-149.

6. Wisloff U, Stoylen A, Loennechen JP, Bruvold M, Rognmo O, et al. (2007) Superior cardiovascular effect of aerobic interval training versus moderate continuous training in heart failure patients: a randomized study. Circulation 115: 3086-3094.

7. Helgerud J, Hoydal K, Wang E, Karlsen T, Berg P, et al. (2007) Aerobic highintensity intervals improve VO2max more than moderate training. Med Sci Sports Exerc 39: 665-671.

8. Arnardóttir RH, Boman G, Larsson K, Hedenstrom H, Emtner M (2007) Interval training compared with continuous training in patients with COPD. Respir Med 101: 1196-1204.

9. Vogiatzis I, Nanas S, Roussos C (2002) Interval training as an alternative modality to continuous exercise in patients with COPD. Eur Respir J 20: 12-19.
10. Talanian JL, Galloway SD, Heigenhauser GJ, Bonen A, Spriet LL (2007) Two weeks of high-intensity aerobic interval training increases the capacity for fat oxidation during exercise in women. J Appl Physiol 102: 1439-1447.

11. Paganini-Hill A, Kawas $\mathrm{CH}$, Corrada MM (2011) Activities and mortality in the elderly: The Leisure World cohort study. J Gerontol A Biol Sci 66: 559-567.

12. Morris N, Gass G, Thompson M, Conforti D (2003) Physiological responses to intermittent and continuous exercise at the same relative intensity in older men. Eur J Appl Physiol 90: 620-625

13. Nemoto K, Gen-no H, Masuki S, Okazaki K, Nose H (2007) Effects of highintensity interval walking training on physical fitness and blood pressure in middle-aged and older people. Mayo Clin Proc 82: 803-811.

14. Janz KF (2006) Physical activity in epidemiology: moving from questionnaire to objective measurement. Br J Sports Med 40: 191-192.

15. Anderson GF, Hussey PS (2000) Population aging: a comparison among industrialized countries. Health Aff (Millwood) 19: 191-203.

16. Fleg JL, Lakatta EG (1988) Role of muscle loss in the age-associated reduction in VO2 max. J Appl Physiol 65: 1147-1151.

17. Norton K, Olds T, Bowes D, Van Ly S, Gore C (1998) Applying the Sports Medicine Australia pre-exercise screening procedures: who will be excluded? J Sci Med Sport 1: 38-51.

18. Phibbs BP, Buckels LJ (1975) Comparative yield of ECG leads in multistage stress testing. Am Heart J 90: 275-276.

19. Tanaka H, Monahan KD, Seals DR (2001) Age-predicted maximal heart rate revisited. J Am Coll Cardiol 37: 153-156.

20. Thompson WR, Gordon NF, Pescatello LS, American college of sports medicine, et al. (2010) ACSM's guidelines for exercise testing and prescription: Wolters Kluwer/Lippincott Williams \& Wilkins.

21. Borg G (1970) Perceived exertion as an indicator of somatic stress. Scand $J$ Rehabil Med 2: 92-98.

22. McGarvey W, Jones R, Petersen S (2005) Excess post-exercise oxygen consumption following continuous and interval cycling exercise. Int J Sport Nutr Exerc Metab 15: 28-37.

23. Ziegendfuss TN, Sedlock DA (1992) Excess post-exercise oxygen consumption following continuous and interval cycling exercise. Medicine \& Science in Sports \& Exercise 24: S97

24. Borsheim E, Bahr R (2003) Effect of exercise intensity, duration and mode on post- exercise oxygen consumption. Sports Med 33: 1037-1060.

25. Smith J, Mc Naughton L (1993) The effects of intensity of exercise on excess postexercise oxygen consumption and energy expenditure in moderately trained men and women. Eur J Appl Physiol Occup Physiol. 67: 420-425.

26. Elliot DL, Goldberg L, Kuehl KS (1992) Effect of resistance training on excess post- exercise oxygen consumption. The Journal of Strength \& Conditioning Research 6: 77.

27. Bahr R, Ingnes I, Vaage O, Sejersted OM, Newsholme EA (1987) Effect of duration of exercise on excess postexercise $\mathrm{O} 2$ consumption. J Appl Physiol 62: 485-490. 